\title{
Studies on Ion-Exchange Properties of Polyaniline Zr(IV) Tungstoiodophosphate Nanocomposite Ion Exchanger
}

\author{
K. Jacinth Mispa, ${ }^{1}$ P. Subramaniam, ${ }^{1}$ and R. Murugesan ${ }^{2}$ \\ ${ }^{1}$ Research Department of Chemistry, Aditanar College of Arts and Science, Tiruchendur, Tamilnadu 628 216, India \\ ${ }^{2}$ Department of Chemistry, T.D.M.N.S. College, Kallikulam, Tamilnadu 627 113, India
}

Correspondence should be addressed to K. Jacinth Mispa; mispajacinth@yahoo.com

Received 22 March 2013; Revised 31 July 2013; Accepted 6 August 2013

Academic Editor: José R. d’Almeida

Copyright ( $2013 \mathrm{~K}$. Jacinth Mispa et al. This is an open access article distributed under the Creative Commons Attribution License, which permits unrestricted use, distribution, and reproduction in any medium, provided the original work is properly cited.

\begin{abstract}
Organic-inorganic hybrid materials prepared by sol-gel approach have attracted a great deal of attention in material science. Organic polymeric part of the composite provides mechanical and chemical stability whereas the inorganic part supports the ion-exchange behaviour and thermal stability and also increases the electrical conductivity. Such modified composite materials can be applied as an electrochemically switchable ion exchanger for water treatment, especially water softening. Polyaniline zirconium(IV) tungstoiodophosphate nanocomposite ion exchanger is prepared by sol-gel method. Polyaniline zirconium(IV) tungstoiodophosphate nanocomposite ion exchanger is synthesized and characterized by Fourier transform-infrared spectra, ultraviolet-visible spectra, X-ray diffraction, scanning electron microscopy, thermogravimetric analysis, ion exchange, conductivity, and antimicrobial studies. A mechanism for the formation of the polyaniline zirconium(IV) tungstoiodophosphate nanocomposite ion exchanger was discussed. The route reported here may be used for the preparation of other nanocomposite ion exchangers.
\end{abstract}

\section{Introduction}

Organic-inorganic hybrid materials prepared by sol-gel approach have attracted a great deal of attention in material science. Organic polymeric part of the composite provides mechanical and chemical stability whereas the inorganic part supports the ion-exchange behaviour, thermal stability and also increases the electrical conductivity. Such modified composite materials can be applied as electrochemically switchable ion exchanger $[1,2]$ for water treatment, especially water softening. The synthesis of hybrid ion exchangers with controlled functionality and hydrophobicity could open new avenues for organometallic chemistry, catalysis, organic hostguest chemistry, analytical chemistry [3-5], hydrometallurgy, antibiotic purification, separation of radioactive isotopes and large scale application in water treatment and pollution control $[6,7]$. Thus, organic-inorganic hybrid materials are expected to provide many possibilities as new composite materials. Accordingly, the hybrid can be used to modify organic polymer materials or to modify inorganic glassy materials. In addition to these characteristics, the hybrid materials can be considered as new composite materials that exhibit very different properties from their original components, that is, organic polymer and inorganic materials especially in the case of molecular level hybrids. Thus, the synthesis of polymeric/inorganic composites has received a great deal of attention because it provided new materials with special mechanical, chemical, electrochemical, and optical as well as magnetic properties [8-11].

A few such excellent ion exchange materials have been developed and are successfully being used in chromatographic techniques [12-14]. An inorganic ion exchanger based on organic polymeric matrix is an interesting material, as it possesses the mechanical stability due to the presence of organic species and the basic characteristics of an inorganic ion exchanger regarding its selectivity for some particular metal ions [15-17]. It was therefore considered to synthesize such hybrid ion exchangers with a good ion exchange capacity, high stability, reproducibility, and selectivity for heavy metal ions, indicating that they are useful in environmental applications. Synthetic ion exchangers based on tetravalent metals have been the objects of considerable study in recent 
years because of their selectivity and intercalation properties. Zirconium based ion exchangers have received attention because of their excellent ion-exchange behaviour and some important chemical applications in the field of ion exchange, ion-exchange membrane, and solid state electrochemistry [18]. Goward et al. [19] have reported that polyaniline $\mathrm{Zr}$ (IV) tungstophosphate nanocomposite ion exchanger was used for the selective separation of $\mathrm{La}^{3+}$ and $\mathrm{UO}_{2}{ }^{2+}$. The literature reveals that several three-component ion exchangers, that is, zirconium(IV) iodooxalate, zirconium(IV) phosphosilicate, zirconium(IV) phosphoborate, and zirconium(IV) tungstophosphate [20], behaviour studied for their synthesis, ion-exchange behavior, and analytical applications. This work deals with the synthesis, characterization, and the study of ion-exchange properties of polyaniline $\mathrm{Zr}(\mathrm{IV})$ tungstoiodophosphate as a new ion exchanger.

\section{Materials and Methods}

2.1. Synthesis of Zirconium(IV) Tungstoiodophosphate. Zirconium(IV) tungstoiodophosphate ion exchanger was prepared by mixing $1.61 \mathrm{~g}$ of zirconium oxychloride octahydrate $(0.1 \mathrm{M})$ in $50 \mathrm{~mL}$ of $4 \mathrm{~N}$ hydrochloric acid solution. This was added to a solution containing $5.4 \mathrm{~g}$ of potassium iodate $(0.5 \mathrm{M})$ and $8.3 \mathrm{~g}$ of sodium tungstate $(0.5 \mathrm{M})$ in $100 \mathrm{~mL}$ of water at the flow rate of $0.5 \mathrm{~mL} \mathrm{~min}^{-1}$. To the resulting mixture, $50 \mathrm{~mL}$ of $1 \mathrm{M}$ orthophosphoric acid was added by maintaining the $\mathrm{pH}$ as 1 with constant stirring using a magnetic stirrer at room temperature. The white gel obtained was filtered off, washed thoroughly with distilled water to remove excess acid and was dried in an air oven at $60^{\circ} \mathrm{C}$.

2.2. Preparation of Polyaniline- $\mathrm{Cl}^{-}$. Polyaniline was prepared from aniline by in situ chemical oxidative polymerization technique using potassium perdisulphate (KPS) as an oxidant. Polymerization was effected at room temperature by drop-wise addition of the oxidant $(0.1 \mathrm{M})$ in water to the continuously stirred solution of aniline $(0.1 \mathrm{M})$ in hydrochloric acid for an hour. After the addition of the oxidant, polymerization was allowed to proceed further for 24 hours in a refrigerator. The formed precipitate was filtered, washed with distilled water, methanol, and acetone repeatedly until the filtrate became colourless, and was dried in an air oven at $60^{\circ} \mathrm{C}$. The dried greenish black powder of polyaniline- $\mathrm{Cl}^{-}$ was ground into a fine powder.

\subsection{Preparation of Polyaniline Zirconium(IV) Tungstoiodo-} phosphate. The composite ion exchanger was prepared by the sol-gel mixing of polyaniline, an organic conducting polymer with the inorganic precipitate of zirconium(IV) tungstoiodophosphate [21-23]. In this process, in situ polymerization of aniline $(0.1 \mathrm{M})$ in the presence of $100 \mathrm{mg}$ of zirconium(IV) tungstoiodophosphate was carried out using $0.1 \mathrm{M}$ KPS as oxidant. Polymerization was effected by dropwise addition of $5.7 \mathrm{~g}$ of the oxidant in $100 \mathrm{~mL}$ of water to the continuously stirred solution of aniline and zirconium(IV) tungstoiodophosphate in $1 \mathrm{~N}$ hydrochloric acid for an hour. After addition of all potassium perdisulphate, polymerization was allowed to proceed further for 24 hours in a refrigerator.
The resultant mixture was turned slowly into greenish black coloured slurry. The polyaniline composite gels were filtered off and washed thoroughly with distilled water to remove the excess acid and any adhering trace of potassium perdisulphate. The product was dried in air oven at $60^{\circ} \mathrm{C}$. The dried gel was put into the distilled water to obtain granules of uniform size. The washed gels were dried at $60^{\circ} \mathrm{C}$ in an air oven. The dried granules were converted into the $\mathrm{H}^{+}$form by keeping them immersed in $1 \mathrm{M}$ nitric acid for 24 hours with occasional shaking and intermittently replacing the supernatant liquid with fresh acid. The material thus obtained was then washed with distilled water to remove the excess acid before drying finally at $60^{\circ} \mathrm{C}$.

2.4. Characterisation. Polyaniline $\mathrm{Zr}(\mathrm{IV})$ tungstoiodophosphate nanocomposite ion exchanger and $\mathrm{H}^{+}$form of conducting polymeric-inorganic hybrid ion exchanger were characterized by FT-IR spectra, UV-visible spectra, X-ray diffraction, SEM, TGA, and conductivity studies. AC electrical conductivity measurement was done on the pelletized samples by using Digital LCR meter (Pacific, Model: PLCR $8 \mathrm{C}$ ) at different temperatures. UV-visible spectra of the synthesized samples were recorded at room temperature in different solvents, namely, NMP, chloroform, o-cresol, and DMSO in 300-900 nm range with Elico model SL-164 Double Beam UV-visible spectrophotometer. FT-IR spectra of conducting organic polymer, inorganic ion exchanger, and conducting polymer-inorganic hybrid ion exchanger were taken by $\mathrm{KBr}$ disc method at room temperature performed on NEXUS-670 FT-IR spectrophotometer. The powder X-ray diffraction technique has been employed to identify the crystalline phases of the samples using monochromatized $\mathrm{Cu}-\mathrm{K}_{\propto}$ $(\lambda=1.5056 \AA)$ on X-ray diffractometer (Model: PW3040/60 X'pert PRO) at a $0.2^{\circ}$ scan rate (in $2 \theta$ ). SEM was performed on ground materials by an electron microscope JEOL Model JSM-6390LV at various magnifications ( $5 \mathrm{x}$ to $300,000 \mathrm{x}$ ). TGA studies of the conducting polymeric composite materials in the original form were carried out by an automatic thermobalance on heating the material from $30^{\circ} \mathrm{C}$ to $1000^{\circ} \mathrm{C}$ at a constant rate of $10^{\circ} \mathrm{C} \mathrm{min}^{-1}$ in the nitrogen atmosphere with Perkin Elmer, Diamond Thermogravimetric Analyzer.

\section{Studies of Ion-Exchange Properties of PANI Zirconium(IV) Tungstoiodophosphate}

3.1. Ion Exchange Capacity (IEC). For the determination of ion-exchange capacity, one gram of the dry cation exchanger in $\mathrm{H}^{+}$form was taken into a glass column. The bed length was approximately $1.5 \mathrm{~cm}$ long. $1 \mathrm{M}$ alkali metal chlorides $(\mathrm{LiCl}$, $\mathrm{NaCl}$, and $\mathrm{KCl}$ ) were used to elute the $\mathrm{H}^{+}$ions completely from the cation exchange columns maintaining a very slow flow rate of $\sim 0.5 \mathrm{~mL} \mathrm{~min}{ }^{-1}$. The effluents were titrated against standard $0.1 \mathrm{M} \mathrm{NaOH}$ solution for the total ions liberated in the solutions using phenolphthalein indicator.

3.2. Effect of Eluent Concentration on IEC. To find out the optimum concentration of eluent for complete elution of $\mathrm{H}^{+}$ions, a fixed volume $(250 \mathrm{~mL})$ of $\mathrm{LiCl}, \mathrm{NaCl}$, and $\mathrm{KCl}$ solutions of varying concentrations $(0.2-1.8 \mathrm{M})$ was passed 
through a column containing $1 \mathrm{~g}$ of the exchanger in $\mathrm{H}^{+}$form with a flow rate of $\sim 0.5 \mathrm{~mL} \mathrm{~min}^{-1}$. The effluent was titrated against standard alkali solution of $0.1 \mathrm{M} \mathrm{NaOH}$ for the $\mathrm{H}^{+}$ ions eluted out for the determination of eluent concentration using phenolphthalein as an indicator.

3.3. Elution Behavior. A column containing $1 \mathrm{~g}$ of the exchanger in $\mathrm{H}^{+}$form was eluted with $1.4 \mathrm{M}$ of $\mathrm{LiCl}, 1.4 \mathrm{M}$ of $\mathrm{NaCl}$ and $1.2 \mathrm{M}$ of $\mathrm{KCl}$ solutions of different $10 \mathrm{~mL}$ fractions with minimum flow rate of $0.5 \mathrm{~mL} \mathrm{~min}^{-1}$. Each fraction of $10 \mathrm{~mL}$ effluent was titrated against standard $\mathrm{NaOH}(0.1 \mathrm{M})$ solution to determine the strength of $\mathrm{H}^{+}$ions eluted out.

3.4. Effect of Time on IEC. The optimum shaking time of ion exchanger with $\mathrm{LiCl}, \mathrm{NaCl}$, and $\mathrm{KCl}$ solutions for complete elution of $\mathrm{H}^{+}$ions was also determined. $0.25 \mathrm{~g}$ of the ion exchanger was shaken with $25 \mathrm{~mL}$ of alkali metal chloride solutions ( $\mathrm{LiCl}, \mathrm{NaCl}$, and $\mathrm{KCl}$ ), and the amount of liberated $\mathrm{H}^{+}$ions was titrated against the standard $\mathrm{NaOH}$ solution after every half an hour interval.

3.5. $p H$ Titration. The $\mathrm{pH}$ titration studies of PANI $\mathrm{Zr}(\mathrm{IV})$ tungstoiodophosphate was performed by the method of Topp and Pepper [24]. A total of $200 \mathrm{mg}$ portions of the cation exchanger in the $\mathrm{H}^{+}$form were placed in each of the several $250 \mathrm{~mL}$ conical flasks followed by the addition of equimolar solutions of alkali metal chlorides $(\mathrm{LiCl}, \mathrm{NaCl}$, and $\mathrm{KCl}$ ) and their hydroxides ( $\mathrm{LiOH}, \mathrm{NaOH}$, and $\mathrm{KOH})$ in different volume ratios; the final volume was kept as $50 \mathrm{~mL}$ to maintain the ionic strength constant. The $\mathrm{pH}$ of the solution was recorded every 24 hours until equilibrium was attained which needed 5 days.

3.6. Selectivity (Sorption) Studies. The distribution behaviour of metal ions plays an important role in the determination of the selectivity of the material. The distribution coefficient ( $K_{d}$ values) of various metal ions on cation exchangers can be determined as follows. $200 \mathrm{mg}$ of the composite cation exchanger beads in the $\mathrm{H}^{+}$form was taken with $20 \mathrm{~mL}(0.005 \mathrm{M})$ of different metal nitrate solutions, $\mathrm{PbNO}_{3}$, $\mathrm{Co}\left(\mathrm{NO}_{3}\right)_{2}$, and $\mathrm{Cu}\left(\mathrm{NO}_{3}\right)_{2}$ and kept for 24 hours with continuous shaking for 6 hours in a shaker at $25 \pm 2^{\circ} \mathrm{C}$ to attain equilibrium. The metal ions in the solution before and after equilibrium were determined by titrating against standard $0.005 \mathrm{M}$ solutions of EDTA [25]. The distribution coefficient is the measure of a fractional uptake of metal ions competing for $\mathrm{H}^{+}$ions form a solution by an ion-exchange material and mathematically calculated using the formula

$$
K_{d}=\frac{(I-F)}{F} \times \frac{V}{m},
$$

where $I$ and $F$ are the initial and final amounts of metal ion in aqueous phase $(\mathrm{M}), V$ is the volume of the solution $(\mathrm{mL})$, and $m$ is the amount of cation exchanger (g).

\section{Results and Discussion}

In the present study, new and novel organic-inorganic electrically conducting nanocomposite cation exchanger was
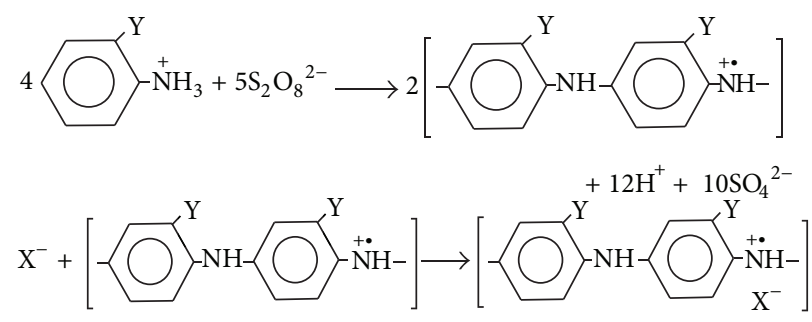

Conducting polymer

Conducting polymeric-inorganic ion exchanger

Where, $\mathrm{Y}=\mathrm{H} \rightarrow$ aniline; $\mathrm{X}=\mathrm{Zr}(\mathrm{IV})$ tungstoiodophosphate

Scheme 1: Polymerisation reaction with the ion exchanger as the dopant.

chemically prepared by sol-gel mixing of organic conducting polymer, polymer (polyaniline) into the matrix of inorganic ion exchanger, $\mathrm{Zr}$ (IV) tungstoiodophosphate. The different steps involved in the mechanism for the formation of conducting polymeric-inorganic nanocomposite ion exchanger are shown in Scheme 1. Polyaniline gel was prepared by oxidation coupling of monomers using $\mathrm{K}_{2} \mathrm{~S}_{2} \mathrm{O}_{8}$ in acidic medium. The binding of polyaniline into the matrix of $\mathrm{Zr}(\mathrm{IV})$ tungstoiodophosphate is possible due to ionic interaction between the radical cation of polyaniline and an ionic group, $\mathrm{Zr}(\mathrm{IV})$ tungstoiodophosphate.

4.1. Electrical Conductivity Studies. From the capacitance obtained from the instrument and thickness as well as the diameter of the pellet, the AC electrical conductivity of the polyaniline $\mathrm{Zr}(\mathrm{IV})$ tungstoiodophosphate sample was calculated using the following equation:

$$
\begin{gathered}
C_{o}=\frac{A \varepsilon_{0}}{d} \\
\varepsilon_{r}=\frac{C}{C_{o}} \\
\sigma=2 \pi f \varepsilon_{0} \varepsilon_{r} \tan \delta,
\end{gathered}
$$

where $\sigma_{\mathrm{ac}}$ is the AC electrical conductivity $\left(\mathrm{S} / \mathrm{cm}^{-1}\right) ; f$ the frequency $(\mathrm{Hz}) ; \varepsilon_{0}$ the permittivity in free space $(8.85 \times$ $\left.10^{-12} \mathrm{f} / \mathrm{m}\right) ; \varepsilon_{r}$ the relative permittivity $(\mathrm{f} / \mathrm{m}) ; \tan \delta$ the tangent loss (or) dielectric loss; $C$ the capacitance at particular temperature (Faradays); $C_{0}$ the capacitance at absolute temperature (Faradays); $A$ the area of the sample $\left(\mathrm{m}^{2}\right) ; d$ the thickness of the sample (m); $r$ the radius of the sample (m).

The capacitance and conductance of the material over a range of temperature and frequency are then calculated from the relationship between the applied voltage and measured current and are related to relative permittivity $\left(\varepsilon_{r}\right)$ and the dielectric loss factor $(\tan \delta)$, respectively. Dielectric loss or tangent loss (dissipation factor) is the tangent of the loss angle when a dielectric is subject to a sinusoidally varying applied electric field. Since $\tan \delta$ is equal to the ratio of the imaginary loss to the real (storage) relative permittivity, it is also the ratio of the energy dissipated to the energy stored for each 


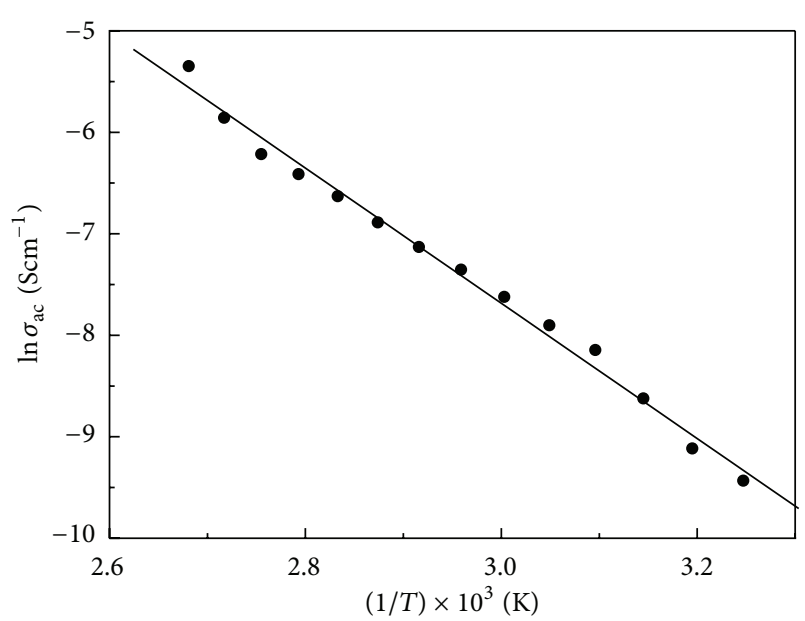

Figure 1: Arrhenius plot for polyaniline Zr(IV) tungstoiodophosphate ion exchanger.

cycle. $\tan \delta$ is high frequency and temperature dependent, and reaching a maximum value as a dielectric relaxation is passed. Dielectric permittivity is a measure of the energy stored in a material subjected to electrical, stress that is, the ability of an insulator or semiconductor to resist the passage of alternating current or serve as a capacitor.

4.2. Charge Transport Properties of PANI and Polyaniline $\mathrm{Zr}(I V)$ Tungstoiodophosphate. The conductivity of chemically synthesized PANI and its samples presented in Table 1 , depends on a number of parameters such as temperature, protonation, and oxidation state [26-32]. The emeraldine salt form of PANI has the electrical conductivity 5.893 $\times 10^{-3} \mathrm{Scm}^{-1}$, which is having high electrical conductivity when compared with that of emeraldine base form of PANI which has $5.528 \times 10^{-7} \mathrm{Scm}^{-1}$. The incorporation of $\mathrm{Zr}(\mathrm{IV})$ tungstoiodophosphate into the matrix of conducting organic polymer leads to an increase in conductivity (8.471 $\times 10^{-3} \mathrm{Scm}^{-1}$ ) of this ion exchanger as compared to PANI emeraldine salt.

The conductivity for this organic-inorganic hybrid ion exchanger shows semiconductor behaviour. The linear portion of the graph $\log \sigma$ versus $1 / T$ fits to Arrhenius type equation (3) for this ion exchanger. Figure 1 is a representive of such plot:

$$
\sigma(T)=\sigma_{0} \exp ^{\left(-E_{g} / 2 K T\right)},
$$

where $E_{g}$ is the activation energy of conductivity which is obtained from the slope. $K$ is the Boltzmann's constant, and $\sigma_{0}$ represents the value of $\sigma$ at $1 / T=0$. The variation of conductivity $(\sigma)$ as a function of $1 / T$ at constant frequency is shown in Figure 1. The temperature dependence of conductivity is described in Table 2. The follow up Arrehenius behaviour is regarded as a good approximation to band theory. Further, the temperature dependence of conductivity and the follow up arrehenius behaviour indicate that the conduction in polyaniline hybrid ion exchanger is predominantly performed by variable range hopping process. An increase in the

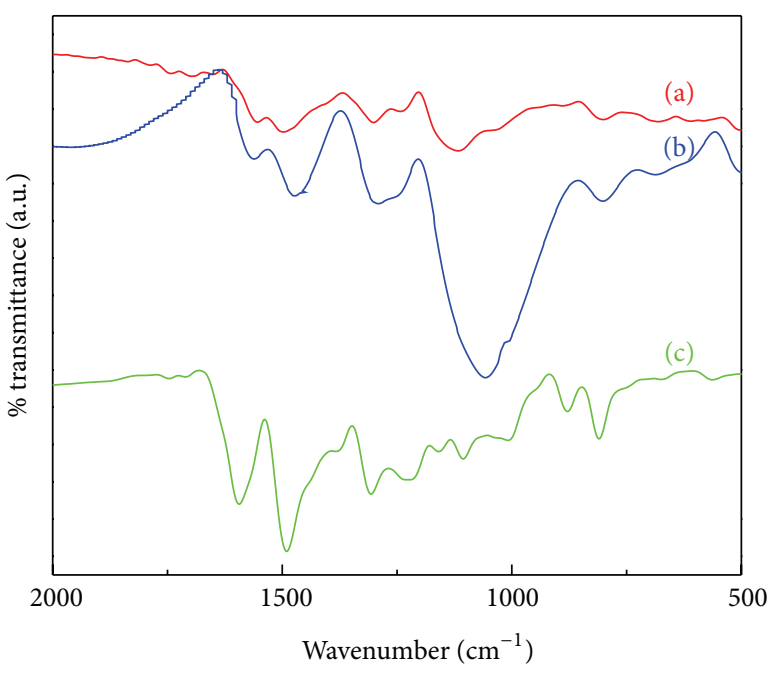

Figure 2

values of the electrical conductivity is driven by an increase in mobility of free charges (i.e., polarons and free ions).

In order to determine the conductivity parameters, the temperature dependence of conductivity (linear portion) is fit to the following equation:

$$
\sigma(T)=\sigma_{0} \exp -\left(\frac{T_{0}}{T}\right)^{1 / 2} .
$$

The activation energy of conductivity for this hybrid ion exchanger was found to be $0.086 \mathrm{eV}$. Actually, the mobility of charge carriers under the influence of an external field up to $100^{\circ} \mathrm{C}$ increases with doping level. The value of activation energy is indicating that the charge carrier has to overcome the same energy barrier while conducting. Thus, the polarons act as charge carrier hopping from state in all the polymer samples.

4.3. FT-IR Spectra. FT-IR spectra are used as a tool to characterize the molecular structures of organic-inorganic hybrid ion exchanger. The FT-IR spectrum of PANI-Cl ${ }^{-}$(a), polyaniline $\mathrm{Zr}(\mathrm{IV})$ tungstoiodophosphate ion exchanger (b), and $\mathrm{H}^{+}$form of polyaniline $\mathrm{Zr}(\mathrm{IV})$ tungstoiodophosphate ion exchanger $(\mathrm{c})$ are given in Figure 2.

The peaks at $1565 \mathrm{~cm}^{-1}$ and $1495 \mathrm{~cm}^{-1}$ are attributed to $\mathrm{C}=\mathrm{N}$ and $\mathrm{C}=\mathrm{C}$ stretching modes for the quinoid and benzenoid rings, the peaks at about $1300 \mathrm{~cm}^{-1}$ and $1231 \mathrm{~cm}^{-1}$ are attributed to $\mathrm{C}-\mathrm{N}$ stretching mode for benzenoid ring, and the peak at $1121 \mathrm{~cm}^{-1}$ is assigned to the plane bending vibration of $\mathrm{C}-\mathrm{H}$ (modes of $\mathrm{N}=\mathrm{Q}=\mathrm{N}, \mathrm{Q}=\mathrm{NH}^{+}-\mathrm{B}$, and $\mathrm{B}-$ $\mathrm{NH}^{+}-\mathrm{B}$ ), and out-plane bending vibrations of PANI are reported to occur at about $801 \mathrm{~cm}^{-1}$.

In the present study also, all the peaks represented above are observed in PANI ZTIP nanocomposite ion exchanger (Table 3), but they are modified in both intensity and peak position when the polymer is incorporated into the inorganic matrix of $\mathrm{Zr}(\mathrm{IV})$ tungstoiodophosphate. An assembly of three peaks in the $500-1000 \mathrm{~cm}^{-1}$ region showed that ionic phosphate groups as well as metal-oxygen bonds are present 
TABLE 1: AC conductivity of various polyaniline samples at room temperature.

\begin{tabular}{|c|c|c|c|c|c|}
\hline Sample & $C$ (nano-or-pico Faradays) & $D$ or $\tan \delta$ & $r(\mathrm{~mm})$ & $d(\mathrm{~mm})$ & $\sigma_{\mathrm{ac}}\left(\mathrm{Scm}^{-1}\right)$ \\
\hline PANI salt & 15.30 (n.f) & 4.90 & 6.69 & 1.78 & $5.893 \times 10^{-3}$ \\
\hline Dedoped PANI & 9.2 (p.f) & 0.96 & 6.73 & 1.42 & $5.528 \times 10^{-7}$ \\
\hline PANI ZrTIP & 16.10 (n.f) & 4.40 & 6.67 & 2.66 & $8.471 \times 10^{-3}$ \\
\hline Dedoped PANI ZTIP & 8.9 (p.f) & 0.57 & 6.67 & 0.84 & $1.916 \times 10^{-7}$ \\
\hline $\mathrm{H}^{+}$form of PANI ZTIP & 17.16 (n.f) & 4.74 & 6.66 & 1.53 & $5.561 \times 10^{-3}$ \\
\hline
\end{tabular}

TABLE 2: Conductivity of polyaniline $\mathrm{Zr}(\mathrm{IV})$ tungstoiodophosphate ion exchanger at different temperatures.

\begin{tabular}{lccccc}
\hline Temp. $\left({ }^{\circ} \mathrm{C}\right)$ & $D$ & $C$ & $\sigma_{\mathrm{ac}}\left(\mathrm{Scm}^{-1}\right)$ & 4.76 & $1000 / T(\mathrm{~K})$ \\
\hline 100 & 0.95 & 41.9 & 2.86 & 2.681 & 2.717 \\
95 & 0.68 & 35.2 & 2.00 & 2.755 & -5.3475 \\
90 & 0.54 & 30.9 & 1.64 & 2.793 & -5.8569 \\
85 & 0.49 & 28.0 & 1.32 & 2.833 & -6.2146 \\
80 & 0.45 & 25.1 & 1.02 & 2.874 & -6.4131 \\
75 & 0.44 & 18.9 & 0.80 & 2.916 & -6.6301 \\
70 & 0.41 & 16.3 & 0.64 & 3.003 & -7.1309 \\
65 & 0.37 & 14.5 & 0.49 & 3.049 & -7.354 \\
60 & 0.33 & 12.1 & 0.37 & 3.096 & -7.6211 \\
55 & 0.29 & 0.8 & 0.29 & 3.145 \\
50 & 0.26 & 7.2 & 0.18 & 3.195 \\
45 & 0.21 & 5.3 & 0.11 & 3.9020 \\
35 & 0.18 & 4.4 & 0.08 & -8.1456 \\
\end{tabular}

in the material [33]. It is also an evidence for the formation of PANI ZTIP nanocomposite ion exchanger.

4.4. UV-Visible Spectroscopy. UV-visible spectra of all the polyaniline samples were recorded at room temperature in solvents like N-methyl pyrrolidone, chloroform, and $\mathrm{m}$ cresol and the peak positions are given in Table 4. The samples exhibit two or three peaks in these solvents. From the UV-visible spectra of the polymer samples in NMP, it is evident that NMP is of a coordinating nature and the polymer samples get coordinated in the protonated $\mathrm{N}$-site after displacing dopant ions and thereby convert salt into base. This observation is also in good agreement with previous reports. The UV-visible spectrum of PANI samples in chloroform has three absorption peaks (<300 nm, $\sim 400 \mathrm{~nm}$, and $\sim 550 \mathrm{~nm})$. From the UV-visible spectra in chloroform and $\mathrm{m}$-cresol, it is clear that polymer chains have different electronic structures in chloroform and $\mathrm{m}$-cresol. This difference in electronic structures can be attributed only to their difference in conformational structures. Specifically, polymer chains of PANI have a more extended conformation and hence a longer conjugation length in $\mathrm{m}$-cresol than in chloroform. The three absortion peaks of polymer samples in chloroform can be assigned as the transition from $\pi$ band to $\pi^{*}$ band, from polaron band to $\pi^{*}$ band, and $\pi$ band to polaron band, respectively.

In m-cresol, the polymer chains of PANI have an extended conformation in which the twist defects between aromatic rings are removed, and hence the interaction between the adjacent polarons becomes stronger. The absorption peak at $550 \mathrm{~nm}$ is associated with the replacement of random coil conformation by intraband transitions within the half filled polaron band. At the same time, between $\pi$ band to $\pi^{*}$ band $(<300 \mathrm{~nm})$ become very weak since the band gap between $\pi$ band and the polaron band has been eliminated. In all solvents, the difference in the peak position is observed when the polymer is incorporated into the inorganic guest matrix.

4.5. X-Ray Diffraction Study. The powder X-ray diffraction technique has been employed to identify the crystalline phases of the samples using monochromatized $\mathrm{Cu}-\mathrm{K}_{\propto}$ $(1.5056 \AA)$. The average crystallite size was measured from $\mathrm{X}$-ray broadening by employing the well-known Scherrer equation, $D=0.96 \lambda / \beta \operatorname{Cos} \theta$ and the value obtained for different PANI samples are given in Table 5. The XRD pattern for PANI-Cl- (a), $\mathrm{H}^{+}$form of polyaniline $\mathrm{Zr}$ (IV) tungstoiodophosphate ion exchanger (b), and polyaniline $\mathrm{Zr}(\mathrm{IV})$ tungstoiodophosphate ion exchanger (c) is given in Figure 3.

4.6. Scanning Electron Microscopy Studies. Scanning electron microscopy was performed on ground materials at various magnifications. SEM images for the polyaniline $\mathrm{Zr}$ (IV) tungstoiodophosphate ion exchanger at various magnifications are shown in Figure 4.

It has been revealed that, after binding of polyaniline with $\mathrm{Zr}$ (IV) tungstoiodophosphate, the morphology has been changed, and the average crystallite size of the composite material was found to be $\sim 75 \mathrm{~nm}$. The X-ray powder diffraction pattern of this ion exchanger suggests an amorphous 
TABLE 3: FT-IR spectral data of the polymer samples.

\begin{tabular}{|c|c|c|c|}
\hline Characterisation & PANI-Cl ${ }^{-}\left(\mathrm{cm}^{-1}\right)$ & PANI ZTIP $\left(\mathrm{cm}^{-1}\right)$ & $\mathrm{H}^{+}$form of PANI ZTIP $\left(\mathrm{cm}^{-1}\right)$ \\
\hline $\begin{array}{l}\mathrm{C}=\mathrm{N} \text { and } \mathrm{C}=\mathrm{C} \text { stretching modes for the } \\
\text { quinoid and benzenoid rings }\end{array}$ & 1565,1495 & 1595,1493 & 1560,1472 \\
\hline $\mathrm{C}-\mathrm{N}$ stretching mode for benzenoid ring & 1300,1231 & 1309,1216 & 1383,1240 \\
\hline In-plane $\mathrm{C}-\mathrm{H}$ bending mode & 1121 & 1152 & 1117 \\
\hline Out of plane $\mathrm{C}-\mathrm{H}$ bending mode & 801 & 811 & 798 \\
\hline Due to $\mathrm{PO}_{4}{ }^{3-}, \mathrm{HPO}_{4}{ }^{2-}$, and $\mathrm{H}_{2} \mathrm{PO}_{4}{ }^{2-}$ & & 1010 & 1000 \\
\hline M-O bond and presence of iodate & & 523,450 & 590,506 \\
\hline
\end{tabular}

TABLE 4: UV-visible absorption data of polyaniline samples in different solvents.

\begin{tabular}{lccc}
\hline \multirow{2}{*}{ Sample } & \multicolumn{3}{c}{ Peak position (nm) } \\
& NMP & $\mathrm{CHCl}_{3}$ & m-Cresol \\
\hline PANI-HCl & $312,575,620$ & $224,428,651$ & 314,556 \\
PANI ZTIP & 308,558 & $226,326,554$ & 312,534 \\
$\mathrm{H}^{+}$form of PANI ZTIP & 319,617 & $243,328,554$ & $330,366,963$ \\
\hline
\end{tabular}

TABLE 5: Average crystallite size of polymer samples.

\begin{tabular}{lc}
\hline Sample & Crystallite size $(\mathrm{nm})$ \\
\hline PANI emeraldine salt & 64 \\
$\mathrm{H}^{+}$form of PANI ZTIP & 78 \\
PANI ZTIP & 75 \\
\hline
\end{tabular}

nature of the composite material. Thus, it was confirmed from both XRD and SEM that the crystallite size shows the nanorange.

4.7. Thermal (TGA) Studies. TGA and DTG (first derivative of TGA) curves for polyaniline emeraldine salt (a) and polyaniline $\mathrm{Zr}(\mathrm{IV})$ tungstoiodophosphate nanocomposite ion exchanger (b) in nitrogen atmosphere are shown in Figure 5. The results reveal a typical three-step weight loss behaviour. For polyaniline, in the first step, $7.0 \%$ weight loss is seen up to $130^{\circ} \mathrm{C}$. This is attributed to the loss of water molecules from the polymer samples. The second weight loss starts at around $120^{\circ} \mathrm{C}$ and ends at around $560^{\circ} \mathrm{C}$. This is attributed to possibly coevolution of acid, as well as the low molecular weight fragments of the polymer. The third step, starting from $560^{\circ} \mathrm{C}$ onwards, represents degradation of the polymer, and this also indicates the decomposition of the backbone of polyaniline. A large weight loss above $560^{\circ} \mathrm{C}$ and up to $1000^{\circ} \mathrm{C}$ was found to be $58.0 \%$ and leaving a marked amount of residue $(42.0 \%$ wt) due to carbonization in nitrogen atmosphere [34].

TGA studies of the composite cation exchange material in the original form were carried out by an automatic thermobalance on heating the material from $40^{\circ} \mathrm{C}$ to $1000^{\circ} \mathrm{C}$ at a constant rate of $10^{\circ} \mathrm{C} \mathrm{min^{-1 }}$ in the nitrogen atmosphere. The thermogravimetric analysis curves, TGA and DTG, reveal a considerable weight loss of about $15.8 \%$ from $40^{\circ} \mathrm{C}$ to $120^{\circ} \mathrm{C}$ in polyaniline $\mathrm{Zr}(\mathrm{IV})$ tungstoiodophosphate nanocomposite ion exchanger, and this can be explained due to the removal of external water molecules. Slow weight loss of the material

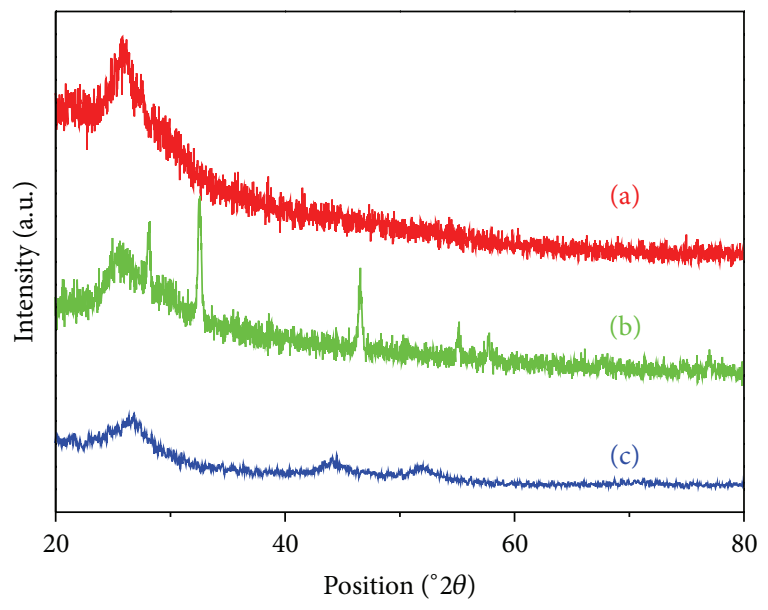

Figure 3

from $120^{\circ} \mathrm{C}$ to about $440^{\circ} \mathrm{C}$ may be due to the removal of dopant as well as conversion of phosphate group to pyrophosphate group [35]. A weight loss of mass observed after $440^{\circ} \mathrm{C}$ is due to decomposition of the organic part of polyaniline. The steep decrease in weight loss in the temperature region $440-700^{\circ} \mathrm{C}$ can be explained as the removal of pyrophosphate group besides thermal decomposition of polyaniline chain. At $900^{\circ} \mathrm{C}$, the decomposition of the polymer has been completed and after $900^{\circ} \mathrm{C}$ the plateau represents the completion of degradation. The residue obtained after $900^{\circ} \mathrm{C}(24.0 \%)$ may be due to carbonization of polyaniline and the formation of metal oxide.

\subsection{Ion-Exchange Properties}

4.8.1. Ion-Exchange Capacity (IEC). The ion-exchange capacity of the hybrid ion exchanger for alkali metal ions increases according to the decrease in the hydrated ionic radii [36-38] as evident from Table 6. Nachod and Wood have also given the similar observations for the exchanged alkali metal ions on carbonaceous zeolite [39]. The maximum ion-exchange capacity sequence for alkali metal ions is $\mathrm{K}^{+}>\mathrm{Na}^{+}>\mathrm{Li}^{+}$. The size of exchanging ion affects IEC of polyaniline $\mathrm{Zr}(\mathrm{IV})$ tungstoiodophosphate nanocomposite ion exchanger.

4.8.2. Effect of Eluent Concentration on IEC. Effect of alkali metal chloride concentration on ion exchange capacity of PANI ZTIP nanocomposite ion exchanger is presented in 
TABLE 6: IEC of various ions on polyaniline $\mathrm{Zr}(\mathrm{IV})$ tungstoiodophosphate ion exchanger.

\begin{tabular}{lcccc}
\hline Exchanging ions & $\mathrm{pH}$ of the metal solution & Ionic radii $(\AA)$ & Hydrated ionic radii $(\AA)$ & Ion-exchange capacity $\left(\mathrm{meq} \cdot \mathrm{dry} \mathrm{g}^{-1}\right)$ \\
\hline $\mathrm{Li}^{+}$ & 3.3 & 0.68 & 3.40 & 4.2 \\
$\mathrm{Na}^{+}$ & 5.0 & 0.97 & 2.76 & 5.3 \\
$\mathrm{~K}^{+}$ & 6.8 & 1.33 & 2.32 & 5.9 \\
\hline
\end{tabular}
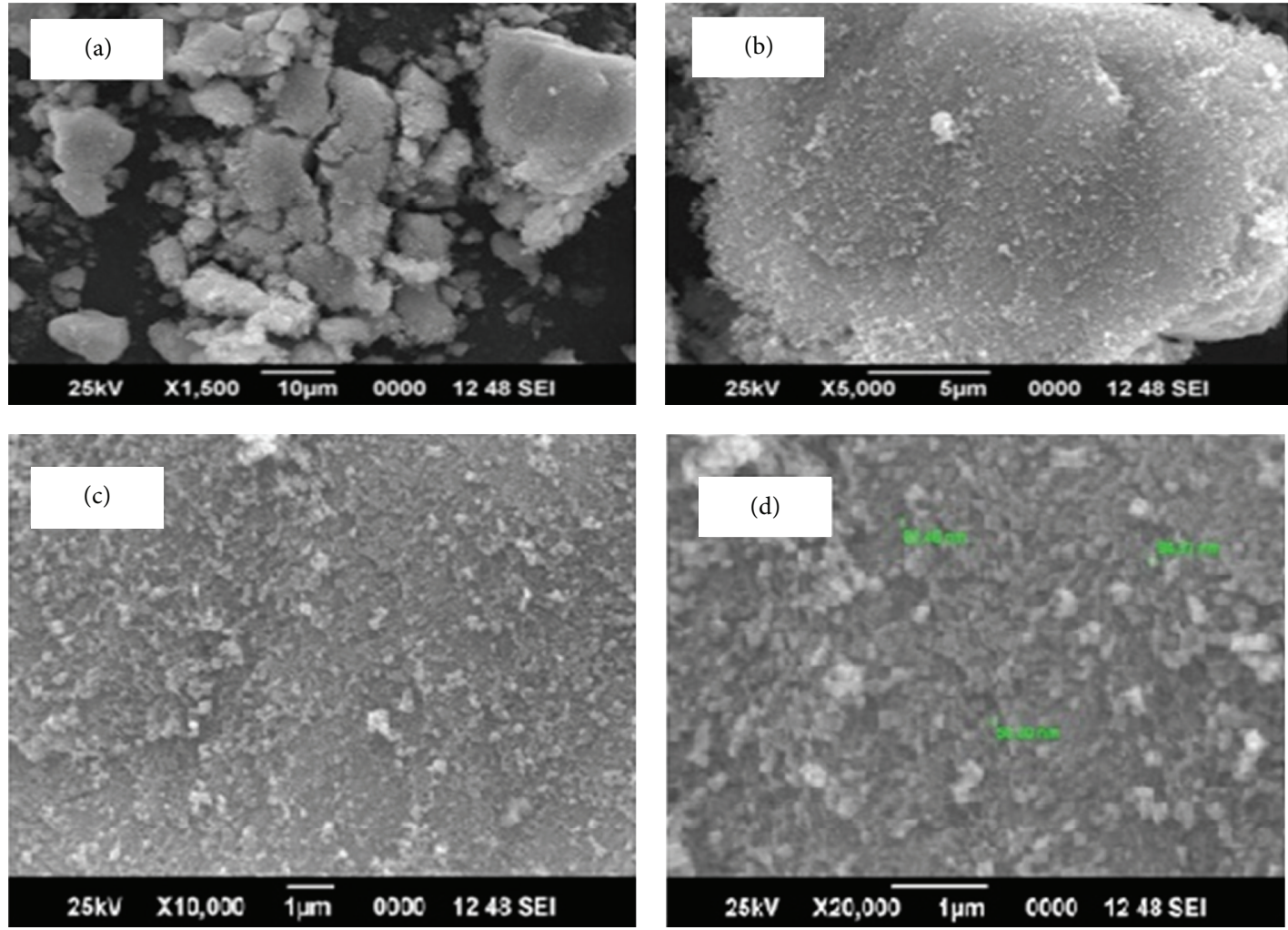

Figure 4

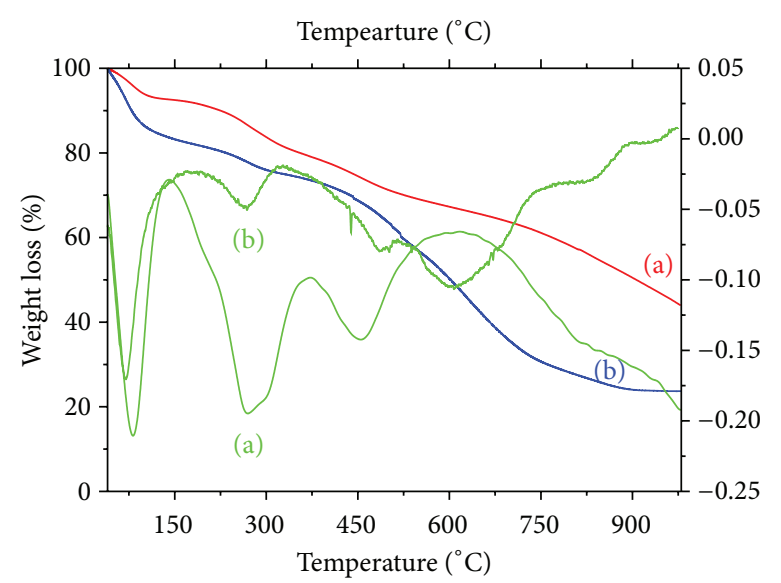

FIGURE 5

Figure 6 and Table 7. The data revealed that the rate of elution increased with the eluent concentration. The highest rate of elution was observed with $1.4 \mathrm{M}, 1.4 \mathrm{M}$, and $1.2 \mathrm{M} \mathrm{LiCl}$, $\mathrm{NaCl}$, and $\mathrm{KCl}$ eluent, respectively, for maximum release of
TABLE 7: Effect of the concentration of eluent on IEC.

\begin{tabular}{lccc}
\hline $\begin{array}{l}\text { Concentration of eluent } \\
(\mathrm{M})\end{array}$ & \multicolumn{3}{c}{ Ion-exchange capacity $(\mathrm{meq} \cdot \mathrm{dry} / \mathrm{g})$} \\
\hline 0.2 & $\mathrm{Li}^{+}$ion & $\mathrm{Na}^{+}$ion & $\mathrm{K}^{+}$ion \\
0.4 & 2.5 & 2.9 & 3.5 \\
0.6 & 2.7 & 3.2 & 3.9 \\
0.8 & 3.0 & 3.6 & 4.3 \\
1.0 & 3.3 & 4.1 & 4.8 \\
1.2 & 3.7 & 4.4 & 5.1 \\
1.4 & 3.9 & 4.8 & 5.9 \\
1.6 & 4.2 & 5.3 & 5.9 \\
1.8 & 4.2 & 5.3 & 5.9 \\
\hline
\end{tabular}

$\mathrm{H}^{+}$ions from polyaniline $\mathrm{Zr}(\mathrm{IV})$ tungstoiodophosphate ion exchanger by using $1 \mathrm{~g}$ of the cation exchanger.

4.8.3. Elution Behaviour. The elution behaviour (Figure 7) indicated that the exchange is quite fast because only $170 \mathrm{~mL}$ of $\mathrm{LiCl}$ solution $(1.4 \mathrm{M}), 150 \mathrm{~mL}$ of $\mathrm{NaCl}$ solution $(1.4 \mathrm{M})$, 
TABLE 8: Elution behavior of polyaniline $\mathrm{Zr}(\mathrm{IV})$ tungstoiodophosphate ion exchanger.

\begin{tabular}{lccc}
\hline \multirow{2}{*}{ Volume of eluent $(\mathrm{mL})$} & \multicolumn{3}{c}{ Strength of $\mathrm{H}^{+}$released (M) } \\
& $\mathrm{LiCl}$ & $\mathrm{NaCl}$ & $\mathrm{KCl}$ \\
\hline 10 & 0.0650 & 0.0740 & 0.0830 \\
20 & 0.0450 & 0.0470 & 0.0440 \\
30 & 0.0380 & 0.0422 & 0.0395 \\
40 & 0.0370 & 0.0390 & 0.0392 \\
50 & 0.0340 & 0.0370 & 0.0228 \\
60 & 0.0330 & 0.0292 & 0.0197 \\
70 & 0.0320 & 0.0289 & 0.0186 \\
80 & 0.0290 & 0.0267 & 0.0175 \\
90 & 0.0290 & 0.0250 & 0.0173 \\
100 & 0.0280 & 0.0240 & 0.0160 \\
110 & 0.0250 & 0.0200 & 0.0150 \\
120 & 0.0240 & 0.0160 & 0.0149 \\
130 & 0.0200 & 0.0156 & 0.0145 \\
140 & 0.0200 & 0.0153 & 0.0140 \\
150 & 0.0180 & 0.015 & 0.0140 \\
160 & 0.0170 & 0.015 & 0.0140 \\
170 & 0.0150 & 0.015 & 0.0140 \\
180 & 0.0150 & 0.015 & 0.0140 \\
190 & 0.0150 & 0.015 & 0.0140 \\
200 & 0.0150 & 0.015 & 0.0140 \\
\hline & & & \\
\hline
\end{tabular}

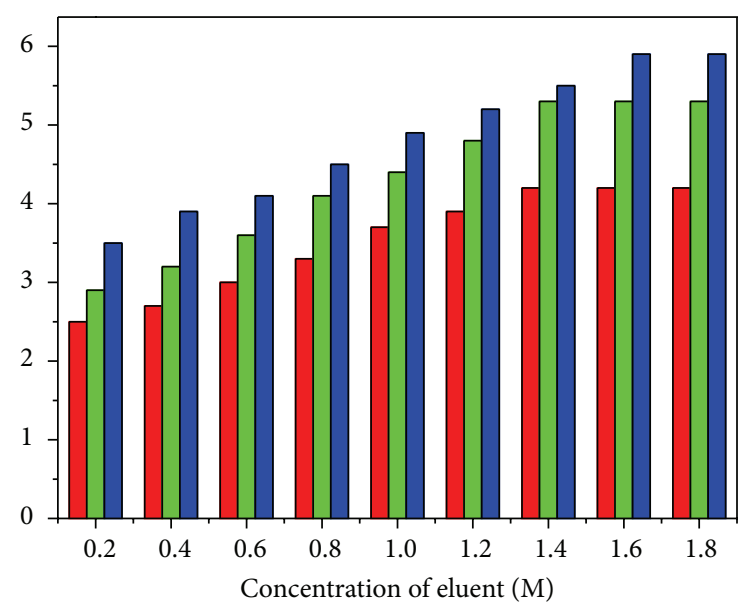

$\square \mathrm{Li}^{+}$

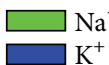

Figure 6: Effect of concentration of eluent on IEC.

and $140 \mathrm{~mL}$ of $\mathrm{KCl}$ solution $(1.2 \mathrm{M})$ are enough to release the total $\mathrm{H}^{+}$from $1 \mathrm{~g}$ of PANI ZrTIP cation-exchange material (Table 8).

4.8.4. Effect of Time on IEC. The effect of elution time on IEC of the hybrid exchanger is shown in Table 9. The effect of equilibration time on exchange capacity of polyaniline $\mathrm{Zr}(\mathrm{IV})$ tungstoiodophosphate nanocomposite ion exchanger using $\mathrm{LiCl}, \mathrm{NaCl}$, and $\mathrm{KCl}$ eluents shows that constant capacity

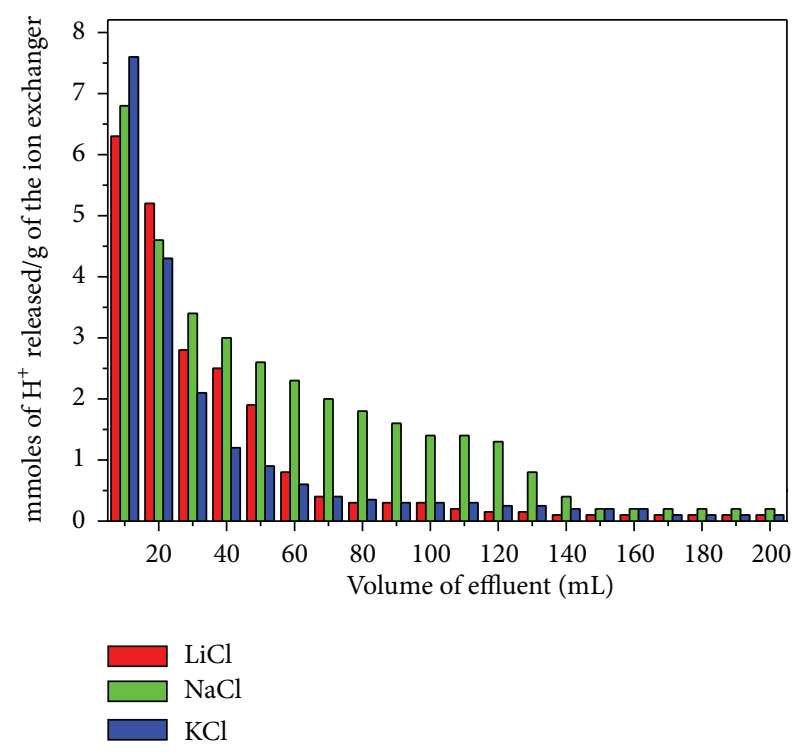

FIGURE 7: Elution behavior of polyaniline Zr(IV) tungstoiodophosphate ion exchanger.

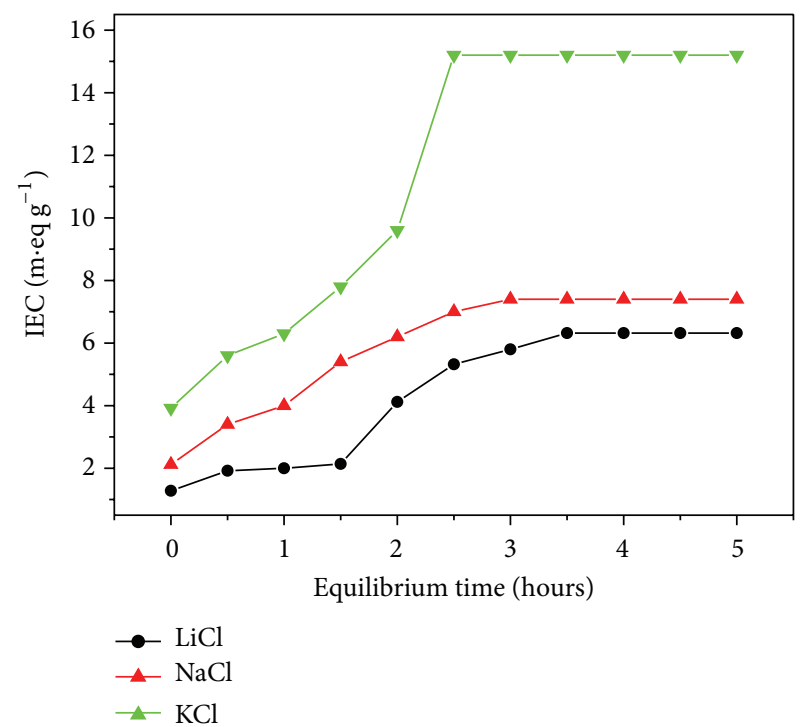

FIgURE 8: Effect of elution time on IEC of polyaniline $\mathrm{Zr}(\mathrm{IV})$ tungstoiodophosphate ion exchanger using (a) $\mathrm{LiCl}$ (b) $\mathrm{NaCl}$ (c) $\mathrm{KCl}$ eluents.

occurs after $3.5,3.0$, and 2.5 hours respectively, and is shown in Figure 8.

4.8.5. $\mathrm{pH}$ Titration. The $\mathrm{pH}$ titration curves for polyaniline $\mathrm{Zr}(\mathrm{IV})$ tungstoiodophosphate nanocomposite ion exchanger were obtained under equilibrium conditions with $\mathrm{LiOH} / \mathrm{LiCl}$, $\mathrm{NaOH} / \mathrm{NaCl}$, and $\mathrm{KOH} / \mathrm{KCl}$ systems indicating bifunctional behaviour of the material as shown in Figure 9.

At low $\mathrm{pH}$, the weak acidic groups remain undissociated. The addition of $\mathrm{LiOH}, \mathrm{NaOH}$, and $\mathrm{KOH}$ neutralized the solution, and the weak acidic group dissociates; thus, the ion exchange starts toward completion. The $\mathrm{pH}$ titration curves 


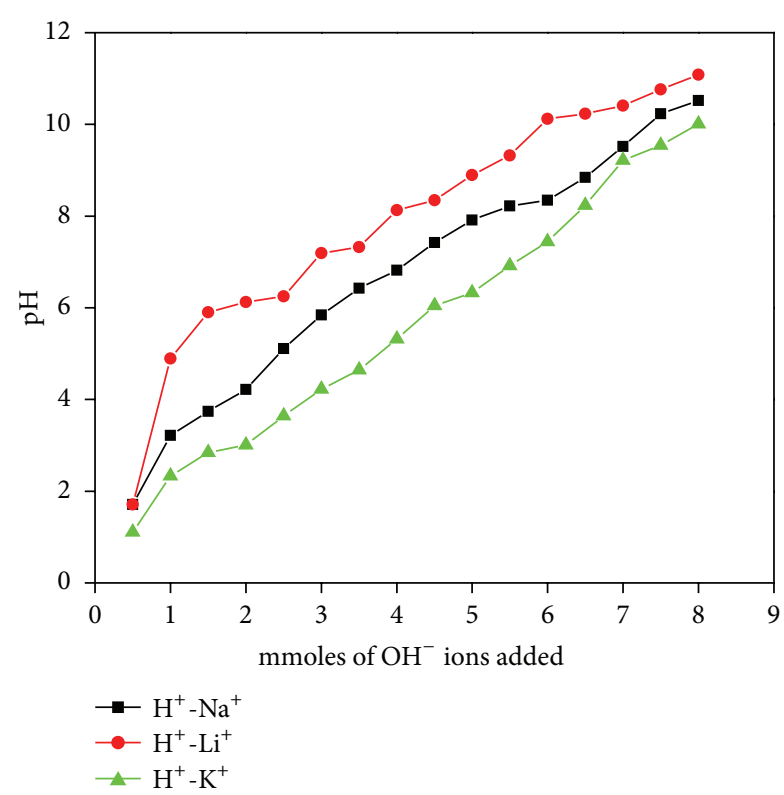

Figure 9: $\mathrm{pH}$ value of polyaniline $\mathrm{Zr}(\mathrm{IV})$ tungstoiodophosphate nanocomposite ion exchanger with various alkali metal hydroxides.

TABLE 9: Effect of elution time on IEC of polyaniline $\mathrm{Zr}$ (IV) tungstoiodophosphate ion exchanger using $\mathrm{LiCl}, \mathrm{NaCl}$, and $\mathrm{KCl}$ eluents.

\begin{tabular}{lccc}
\hline $\begin{array}{l}\text { Equilibrium time } \\
\text { (Hours) }\end{array}$ & $\begin{array}{l}\text { Ion-exchange capacity of ion exchanger } \\
\left(\mathrm{meq} \cdot \mathrm{dry}^{-1} \text { ) }\right. \\
\mathrm{Li}^{+} \text {ion }\end{array}$ & $\mathrm{Na}^{+}$ion & $\mathrm{K}^{+}$ion \\
\hline 0 & 1.28 & 2.12 & 3.92 \\
0.5 & 1.92 & 3.40 & 5.60 \\
1.0 & 2.00 & 4.00 & 6.30 \\
1.5 & 2.14 & 5.40 & 7.80 \\
2.0 & 4.12 & 6.20 & 9.60 \\
2.5 & 5.32 & 7.00 & 15.20 \\
3.0 & 5.80 & 7.40 & 15.20 \\
3.5 & 6.32 & 7.40 & 15.20 \\
4.0 & 6.32 & 7.40 & 15.20 \\
4.5 & 6.32 & 7.40 & 15.20 \\
5.0 & 6.32 & 7.40 & 15.20 \\
\hline
\end{tabular}

showed a gradual rise in $\mathrm{pH}$ initially and a steep rise at the end because strong acidic groups were completely exchanged with $\mathrm{Li}^{+}, \mathrm{Na}^{+}$and $\mathrm{K}^{+}$ions at the end. The rate of $\mathrm{H}^{+}-\mathrm{K}^{+}$exchange was faster than those of $\mathrm{H}^{+}-\mathrm{Na}^{+}$, and $\mathrm{H}^{+}-\mathrm{Li}^{+}$exchanges.

4.8.6. Selectivity (Sorption) Studies. In order to find out the potentiality of polyaniline $\mathrm{Zr}(\mathrm{IV})$ tungstoiodophosphate nanocomposite ion exchanger in the separation of metal ions, distribution studies for three metal ions were performed in four solvent systems. The results of distribution studies (Table 10) show that $K_{d}$ value varies with the nature and composition of contacting solvents. It was also observed from the sorption studies ( $K_{d}$ values) that the composite has a
TABLE 10: Distribution coefficient values of some metal ions on polyaniline $\mathrm{Zr}(\mathrm{IV})$ tungstoiodophosphate in different solvent systems.

\begin{tabular}{lcccc}
\hline \multirow{2}{*}{ Metal ions } & \multicolumn{4}{c}{$K_{d}$ values in different solvent systems } \\
& DMW & $10 \%$ ethanol & $10 \%$ acetone & $1 \mathrm{M} \mathrm{H}_{2} \mathrm{SO}_{4}$ \\
\hline $\mathrm{Pb}^{2+}$ & 265 & 172 & 251 & 51 \\
$\mathrm{Cu}^{2+}$ & 96 & 115 & 122 & 13 \\
$\mathrm{Co}^{2+}$ & 59 & 86 & 37 & 90 \\
\hline
\end{tabular}

TABLE 11: Antimicrobial activity studies of polymer samples.

\begin{tabular}{lcccc}
\hline Organisms & Media & \multicolumn{2}{c}{ Zone of inhibition in (mm) } \\
Colyaniline Zr(IV) \\
Control PANI & $\begin{array}{c}\text { tungstoiodophosphate } \\
\text { ion exchanger }\end{array}$ \\
\hline $\begin{array}{l}\text { Escherichia } \\
\text { coli } \\
\begin{array}{l}\text { Proteus } \\
\text { vulgaris }\end{array}\end{array}$ & Muller & 18 & 15 & 20 \\
\hline
\end{tabular}

maximum selectivity towards $\mathrm{Pb}^{2+}$ than other metal ions like $\mathrm{Cu}^{2+}$ and $\mathrm{Co}^{2+}$.

4.8.7. Studies of Antimicrobial Activity. The antimicrobial activity studies of the PANI and polyaniline $\mathrm{Zr}(\mathrm{IV})$ tungstoiodophosphate nanocomposite ion exchanger were carried out using the Kirby-Bauer antimicrobial susceptibility test procedure [40] against two bacteria, namely, E. coli and Proteus vulgaris (Figure 10). The test solutions of these two samples were prepared in NMP solvent. The antimicrobial activity study results are summarized in the Table 11.

From the table, polymer and the conducting polymericinorganic nanocomposite ion exchanger showed higher antimicrobial activity against E. coli and Proteus vulgaris, and inhibition zones were formed due to their antimicrobial activity.

\section{Conclusions}

The characterization of polyaniline $\mathrm{Zr}$ (IV) tungstoiodophosphate ion exchanger is justified on the basis of FT-IR, UVvisible, XRD, SEM, and TGA. The principle characteristic peaks of quinoid-benzenoid $\mathrm{N}$-moieties, $\mathrm{C}-\mathrm{N}$ stretching, and $\mathrm{C}-\mathrm{H}$ aromatic in-plane and out-plane bending vibrations of PANI are reported to occur at about 1600, 1500, 1350, 1130 , and $820 \mathrm{~cm}^{-1}$, respectively. In the present study also all the peaks are observed in prepared polyaniline $\mathrm{Zr}(\mathrm{IV})$ tungstoiodophosphate nanocomposite ion exchanger using potassium perdisulphate as the oxidant, but they are modified both in intensity and peak position when the ion exchanger is incorporated into the conducting polymeric matrix PANI. XRD pattern of this cation exchanger shows that the composite material is in a semicrystalline form. The SEM images and XRD studies show that the average crystallite size of the $\mathrm{H}^{+}$form of composite material was found to be $78 \mathrm{~nm}$. The thermal analysis points out the inference that prepared polyaniline $\mathrm{Zr}(\mathrm{IV})$ tungstoiodophosphate nanocomposite 


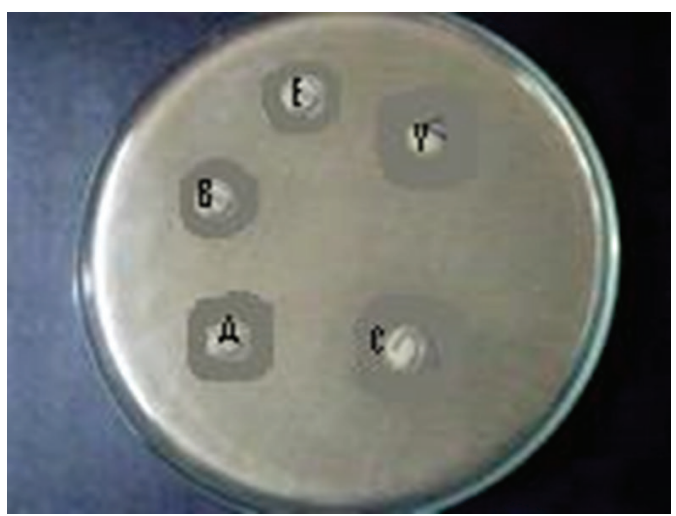

(a)

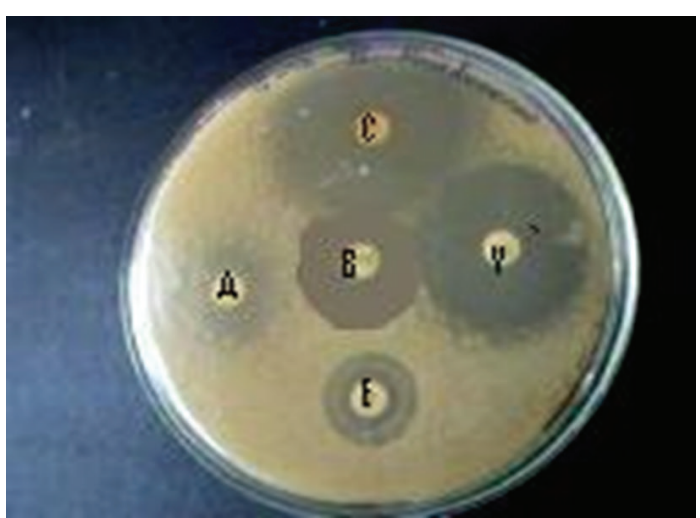

(b)

Figure 10: Zone formation against (a) E. coli and (b) Proteus vulgaris.

ion exchanger is thermally stable. The three different absorption peaks are observed in the UV-visible spectra of the polymer samples due to the transition from $\pi$ band to $\pi^{*}$ band, from polaron band to $\pi^{*}$ band, and from $\pi$ band to polaran band. This indicates that polarons act as charge carriers in all the polymer samples. From the electrical conductivity studies, it is quite clear that organic-inorganic nanocomposite ion exchanger is having good electrical conductivity compared to those of its corresponding organic polymers. The conducting polymeric-inorganic nanocomposite ion exchanger, polyaniline $\mathrm{Zr}(\mathrm{IV})$ tungstoiodophosphate prepared by the sol-gel mixing, has good ion-exchange capacity compared to that of the individual ion exchanger like $\mathrm{Zr}$ (IV) tungstoiodophosphate, which has the ion-exchange capacity of 2.2 m.eq.dry/g. Polyaniline $\mathrm{Zr}(\mathrm{IV})$ tungstoiodophosphate nanocomposite ion exchanger has good ion-exchange capacity towards different metal ions like $\mathrm{Li}^{+}, \mathrm{Na}^{+}$, and $\mathrm{K}^{+}$to the extent of 4.2, 5.3, and 5.9 meq.dry $\mathrm{g}^{-1}$, respectively. The distribution coefficient values from sorption studies show that polyaniline $\mathrm{Zr}(\mathrm{IV})$ tungstoiodophosphate nanocomposite ion exchanger has a higher selectivity towards $\mathrm{Pb}^{2+}$ than towards $\mathrm{Cu}^{2+}$ and $\mathrm{Co}^{2+}$; that is, $\mathrm{Pb}^{2+}$ is highly adsorbed in all solvents while $\mathrm{Cu}^{2+}$ and $\mathrm{Co}^{2+}$ ions are poorly adsorbed. Antimicrobial activity study shows that the organic polymer and nanocomposite ion exchanger are effective against Escherichia coli and Proteius vulgaris.

The intrinsic multifunctional character of organic/inorganic hybrid materials makes them potentially useful in multiple fields. Illustrative examples of this versatility are their high added value applications as coating for corrosion production and abrasion resistance, artificial membranes for ultra- and nanofiltration adsorbents for toxic compounds, and so forth. Most of the organic/inorganic hybrid materials are nanocomposite materials in which the inorganic part and the organic entities interact at the molecular level in the nanoscopic domain. The most obvious advantage of organic and inorganic hybrids is that they have good ion-exchange properties, high stability, reproducibility, and selectivity for heavy toxic metal ions. In the present work, polyaniline $\mathrm{Zr}$ (IV) tungstoiodophosphate is a newly synthesised organicinorganic nanocomposite ion exchanger, which possess all such characteristics and is highly selective for lead, a hazardous toxic metal in the environment. Thus, the material can be used in making $\mathrm{Pb}(\mathrm{II})$ ion selective membrane electrode.

\section{Conflict of Interests}

This study was not supported by any grant. K. Jacinth Mispa, P. Subramaniam, and R. Murugesan report that they have not received any financial support for the research from organizations that may either gain or lose from the publication of this paper.

\section{Acknowledgments}

The authors are grateful to ICP section of CECRI, Karaikudi for allowing the use of XRD measurements. The authors would also like to acknowledge the STIC, Cochin University, and the Department of Physics, Aditanar College of Arts and Science, Tiruchendur, for SEM and conductivity studies, respectively.

\section{References}

[1] T. Shimidzu, A. Ohtani, and K. Honda, "Charge-controllable poly pyrrole/poly electrolyte composite membranes: part III. Electrochemical deionization system constructed by anionexchangeable and cation-exchangeable polypyrrole electrodes," Journal of Electroanalytical Chemistry, vol. 251, no. 2, pp. 323337, 1988.

[2] C. Zhong, K. Doblhofer, and G. Weinberg, "The effect of incorporated negative fixed charges on the membrane properties of polypyrrole films," Faraday Discussions of the Chemical Society, vol. 88, pp. 307-316, 1989.

[3] U. Schybert, N. Husing, and A. Lorenz, "Oxide gels and ceramics prepared by a nonhydrolytic Sol-Gel process," Chemistry of Materials, vol. 7, no. 11, pp. 2110-2114, 1995.

[4] N. K. Raman, M. T. Anderson, and C. J. Brinker, "Templatebased approaches to the preparation of amorphous, nanoporous silicas," Chemistry of Materials, vol. 8, no. 8, pp. 1682-1701, 1996.

[5] J. Wen and G. L. Wilkans, "Organic/inorganic hybrid network materials by the Sol-Gel approach," Chemistry of Materials, vol. 8, no. 8, pp. 1667-1681, 1996. 
[6] F. Helfrich, Ion-Exchange, Mac Graw-Hill, New York, NY, USA, 1962.

[7] R. Kunnin, Ion- Exchange Resins, John Wiley \& Sons, New York, NY, USA, 3rd edition, 1958.

[8] R. Schoolorn, "Intercalation systems as nanostructured functional materials," Chemistry of Materials, vol. 8, no. 8, pp. 17471757, 1996.

[9] P. Gomez-Romero, "Hybrid organic-inorganic materials-in search of synergic activity," Advanced Materials, vol. 13, p. 163, 2001.

[10] Y. Wang and N. Herrom, "X-ray photoconductive nanocomposites," Science, vol. 273, no. 5275, pp. 632-634, 1996.

[11] S. Higashika, K. Kimura, Y. Matsuo, and Y. Sugie, "Synthesis of polyaniline-intercalated graphite oxide," Carbon, vol. 37, no. 2, pp. 354-355, 1999.

[12] A. A. Khan and M. M. Alam, "New and novel organic-inorganic type crystalline "polypyrrolel/polyantimonic acid" composite system: preparation, characterization and analytical applications as a cation-exchange material and $\mathrm{Hg}(\mathrm{II})$ ion-selective membrane electrode," Analytica Chimica Acta, vol. 504, no. 2, pp. 253-264, 2004.

[13] A. A. Khan and Inamuddin, "Preparation, physico-chemical characterization, analytical applications and electrical conductivity measurement studies of an "organic-inorganic" composite cation-exchanger: polyaniline Sn(IV) phosphate," Reactive and Functional Polymers, vol. 66, no. 12, pp. 1649-1663, 2006.

[14] A. A. Khan, Inamuddin, and M. M. Alam, "Determination and separation of $\mathrm{Pb}^{2+}$ from aqueous solutions using a fibrous type organic-inorganic hybrid cation-exchange material: polypyrrole thorium(IV) phosphate," Reactive and Functional Polymers, vol. 63, no. 2, pp. 119-133, 2005.

[15] A. A. Khan and M. M. Alam, "Synthesis, characterization and analytical applications of a new and novel "organic-inorganic" composite material as a cation exchanger and $\mathrm{Cd}(\mathrm{II})$ ionselective membrane electrode: polyaniline $\mathrm{Sn}(\mathrm{IV})$ tungstoarsenate," Reactive and Functional Polymers, vol. 55, no. 3, pp. 277290, 2003.

[16] K. G. Varshney, N. Tayal, A. A. Khan, and R. Niwas, "Synthesis, characterization and analytical applications of lead (II) selective polyacrylonitrile thorium (IV) phosphate: a novel fibrous ion exchanger," Colloids and Surfaces A, vol. 181, no. 1-3, pp. 123129, 2001.

[17] G. Alberti, M. Casciola, C. Dionigi, and R. Vivani, in Proceedings of the International Conference on Ion- Exchange (ICIE '95), Takamtsu, Japan, 1995.

[18] J. C. W. Chien, Polyacetylene-Chemistry, Physics and Materials Science, chapter 2, Academic Press, San Diego, Fla, USA, 1984.

[19] G. R. Goward, F. Leroum, and L. F. Nazir, "Poly(pyrrole) and poly(thiophene)/vanadium oxide interleaved nanocomposites: positive electrodes for lithium batteries," Electrochimica Acta, vol. 43, no. 10-11, pp. 1307-1313, 1998.

[20] P. Singh, J. P. Rawat, and N. Rehman, "Synthesis, characterization and Ion Exchange Properties of a New Inorganic Ion Exchange Materials: Zirconium(IV) iodooxalate," Indian Journal of Chemistry A, vol. 41, p. 1616, 2002.

[21] W. A. Siddiqui and S. A. Khan, "Synthesis, characterization and ion exchange properties of zirconium(IV) tungstoiodophosphate, a new cation exchanger," Bulletin of Materials Science, vol. 30, no. 1, pp. 43-49, 2007.

[22] D. C. Trivedi, "Polyanilines in conductive polymers: synthesis and electrical properties," in Handbook of Organic Conductive
Molecules and Polymers, H. S. Nalwa, Ed., vol. 2, p. 505, John Wiley \& Sons, Chichester, UK, 1997.

[23] A. A. Khan and T. Akhtar, "Preparation, physico-chemical characterization and electrical conductivity measurement studies of an organic-inorganic nanocomposite cation-exchanger: poly-otoluidine $\mathrm{Zr}(\mathrm{IV})$ phosphate," Electrochimica Acta, vol. 53, no. 17, pp. 5540-5548, 2008.

[24] N. E. Topp and K. W. Pepper, "Properties of ion-exchange resins in relation to their structure. Part I. Titration curves," Journal of the Chemical Society, pp. 3299-3303, 1949.

[25] C. N. Reilley, R. W. Schmidt, and F. S. Sadek, "Chelon approach to analysis (I) survey of theory and application," Journal of Chemical Education, vol. 36, p. 555, 1959.

[26] J. P. Travers, J. Chroboczek, F. Devreux, and F. Genoud, "Transport and magnetic resonance studies of polyaniline," Molecular Crystals and Liquid Crystals, vol. 121, no. 1-4, p. 195, 1985.

[27] B. Lundberg, W. R. Salaneck, and LundstromI, "Pressure, temperature and field dependence of hopping conduction in polyaniline," Synthetic Metals, vol. 21, no. 1-3, pp. 143-147, 1987.

[28] W. S. Huang, A. G. Mac Diarmid, and A. J. Epstein, "Polyaniline: non-oxidative doping of the emeraldine base form to the metallic regime," Journal of the Chemical Society, Chemical Communications, no. 23, pp. 1784-1786, 1987.

[29] W. W. Focke, G. E. Wnek, and Y. Wei, "Influence of oxidation state, $\mathrm{pH}$, and counterion on the conductivity of polyaniline," Journal of Physical Chemistry, vol. 91, no. 22, pp. 5813-5818, 1987.

[30] W. W. Focke and G. E. Wnek, "Conduction mechanisms in polyaniline (emeraldine salt)," Journal of Electroanalytical Chemistry, vol. 256, no. 2, pp. 343-352, 1988.

[31] W. R. Salaneck, I. Lundstrom, W. S. Huang, and A. G. Mac Diarmid, "A two-dimensional-surface "state diagram" for polyaniline," Synthetic Metals, vol. 13, no. 4, pp. 291-297, 1986.

[32] R. J. Cushman, P. M. McManus, and S. C. Yang, "Spectroelectrochemical Study of Polyaniline: the construction of a Ph-potential phase diagram," Journal of Electroanalytical Chemistry and Interfacial Chemistry, vol. 291, p. 335, 1986.

[33] C. N. R. Rao, Chemical Applications of Infrared Spectroscopy, Academic Press, New York, NY, USA, 1963.

[34] A. G. MacDiarmid, J. C. Chiang, W. S. Huang, B. D. Hum-phery, and N. L. D. Somasiri, "Polyaniline: protonic acid doping to the metallic regime," Molecular Crystals and Liquid Crystals, vol. 25, p. 309, 1985.

[35] A. A. Khan and T. Akhtar, "Preparation, physico-chemical characterization and electrical conductivity measurement studies of an organic-inorganic nanocomposite cation-exchanger: poly- $o$ toluidine $\mathrm{Zr}(\mathrm{IV})$ phosphate," Electrochimica Acta, vol. 53, no. 17, pp. 5540-5548, 2008.

[36] A. P. Gupta, H. Agarwal, and S. Ikram, "Studies on new composite material polyaniline zirconium (IV) tungstophosphate, Th (IV) selective cation exchanger," Journal of Indian Chemical Society, vol. 80, p. 57, 2003.

[37] S. A. Nabi, A. Islam, and N. Rehman, "Synthesis, ion exchange properties and analytical application of a semi crystalline $\operatorname{Zr}(\mathrm{IV})$ sulphosalicylate," Annales de Chimie Science des Matériaux, vol. 22, no. 7, p. 463, 1997.

[38] J. P. Rawat and J. P. Singh, "Studies on inorganic ion exchangers. II. Synthesis, ion exchange properties, and applications of ferric arsenate," Canadian Journal of Chemistry, vol. 54, no. 16, pp. 2534-2539, 1976.

[39] F. C. Nachod and W. Wood, "The reaction velocity of ion exchange," Journal of the American Chemical Society, vol. 66, no. 8, pp. 1380-1384, 1944. 
[40] G. James, Cappuccino, and N. Sherman, Microbiological Laboratory Manual, Wonder Book, Frederick, Md, USA, 5th edition, 1999. 

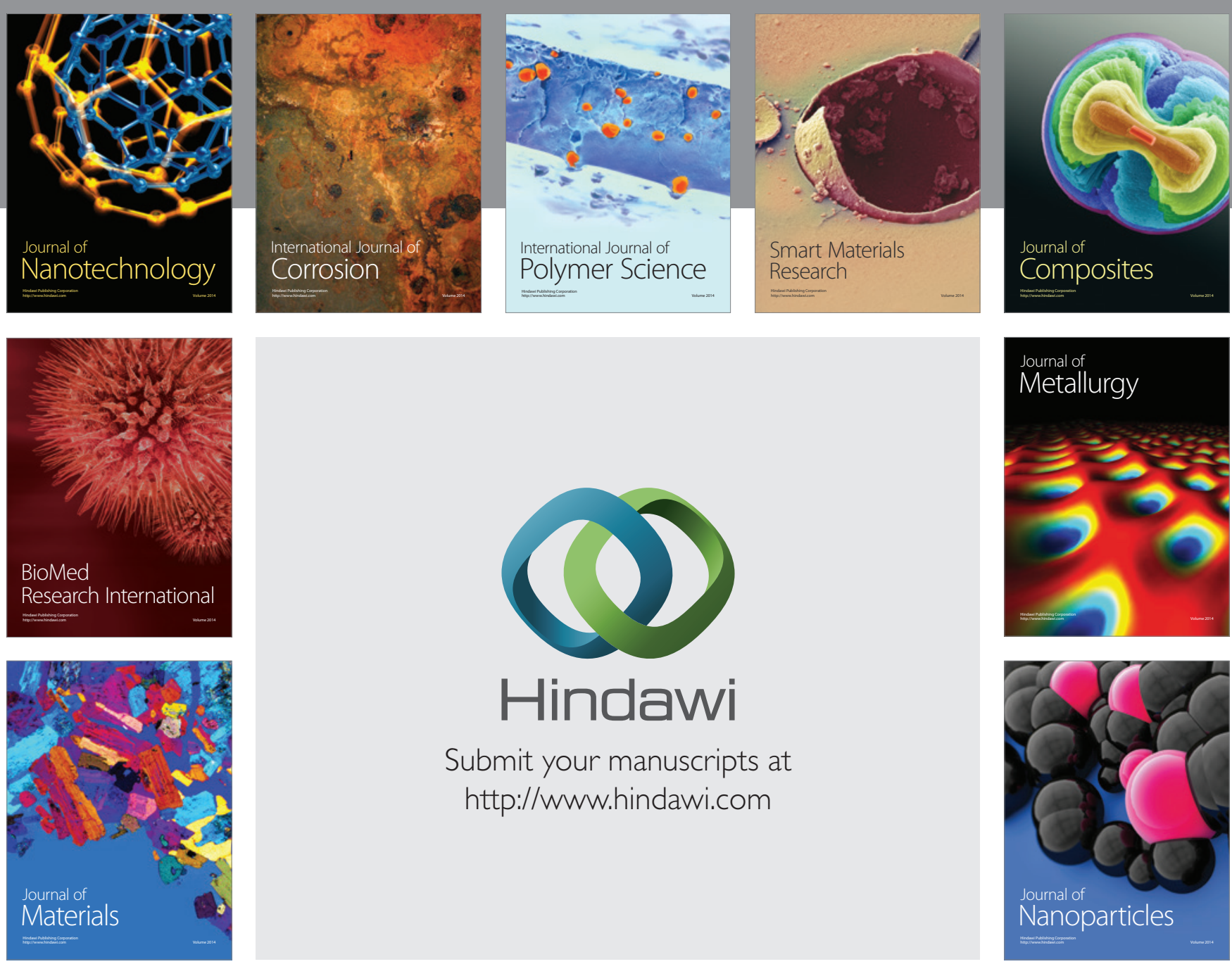

Submit your manuscripts at http://www.hindawi.com
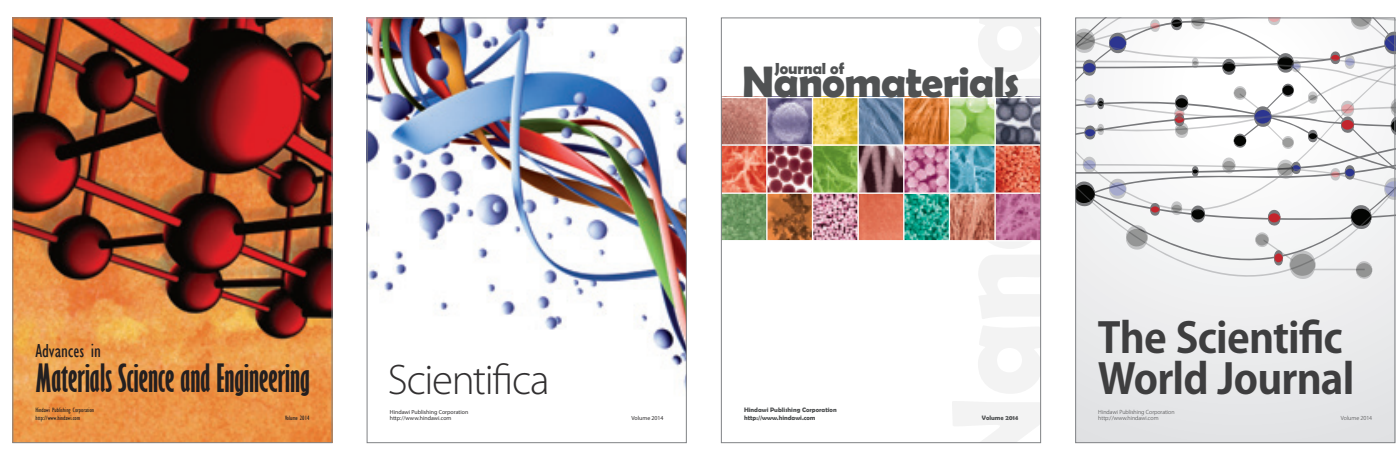

\section{The Scientific World Journal}
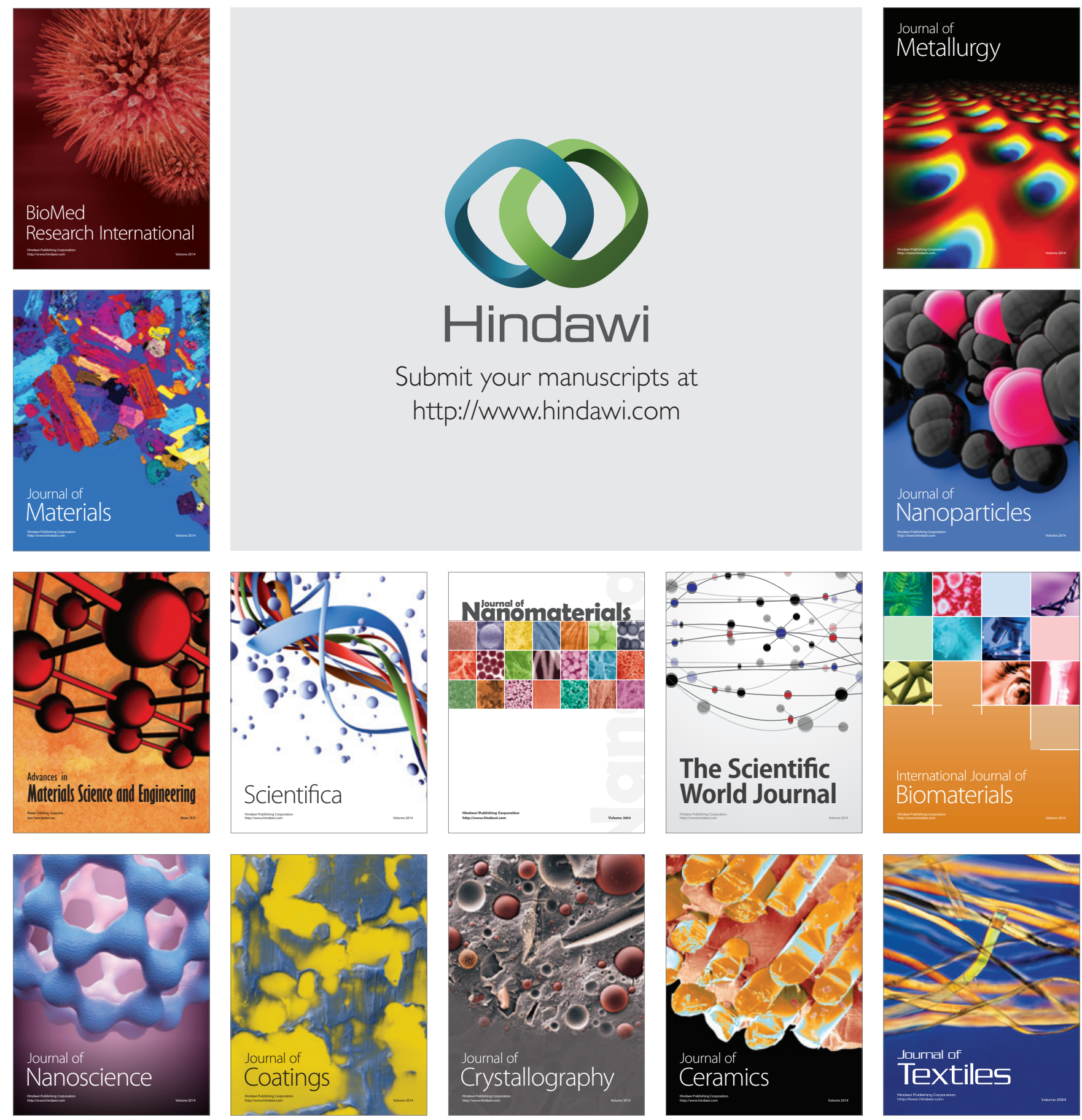